\title{
Anti-allodynic effect of theoesberiven $F$ in a vincristine-induced neuropathy model
}

\author{
SEUNGUK BANG ${ }^{1}$, YEE SUK KIM ${ }^{2}$ and SANG ROK JEONG ${ }^{2}$ \\ ${ }^{1}$ Department of Anesthesiology and Pain Medicine, Daejeon St. Mary's Hospital, College of Medicine, \\ The Catholic University of Korea, Daejeon 301-723; ${ }^{2}$ Department of Anesthesiology and Pain Medicine, \\ Bucheon St. Mary's Hospital, College of Medicine, The Catholic University of Korea, \\ Bucheon, Gyeonggi 463-805, Republic of Korea
}

Received March 11, 2015; Accepted April 19, 2016

DOI: $10.3892 / \mathrm{etm} .2016 .3396$

\begin{abstract}
Allodynia is a main symptom of the peripheral neuropathy induced by vincristine treatment. Theoesberiven $\mathrm{F}$, a combination of Melilotus extract and proxyphylline, is currently used for the treatment of inflammatory conditions due to its potent anti-inflammatory and analgesic properties. The anti-allodynic effect of theoesberiven F on mechanical and cold allodynia in a rat model of vincristine-induced neuropathy was investigated in the present study. Intraperitoneal vincristine injections were administered to male Sprague-Dawley rats at a dose of $0.1 \mathrm{mg} / \mathrm{kg} /$ day over 12 days (5 days of injection, a 2-day cessation and 5 days of injection). Rats that were allodynic following the vincristine injections were randomly allocated into four groups. Normal saline was injected into rats in the control group. Theoesberiven $\mathrm{F}(0.1,0.25$ and $0.5 \mathrm{mg} / \mathrm{kg}$ ) was administered to rats in the three experimental groups, respectively. Mechanical and cold allodynia were measured at preadministration and at 15, 30, 60, 90, 120, 150 and 180 min following the intraperitoneal administration of normal saline or theoesberiven F. The decreased paw withdrawal threshold induced by vincristine injection was increased by theoesberiven $\mathrm{F}$ administration. The increased withdrawal frequency to cold stimuli developed by vincristine was reduced by theoesberiven $\mathrm{F}$ administration. The results of this study suggest that the administration of theoesberiven $\mathrm{F}$ may be beneficial in reducing the mechanical and cold allodynia developed during vincristine treatment.
\end{abstract}

Correspondence to: Dr Yee Suk Kim, Department of Anesthesiology and Pain Medicine, Bucheon St. Mary's Hospital, College of Medicine, The Catholic University of Korea, 2 Sosa-Dong, Wonmi-Gu, Bucheon, Gyeonggi 463-805, Republic of Korea E-mail: knabi_2000@naver.com

Key words: vincristine, neuropathy, theoesberiven F, allodynia, pain

\section{Introduction}

Vincristine is an anticancer agent of the vinca alkaloids class, and has been used for the treatment of patients with leukemia (1). Neurotoxicity is a well-known complication of vincristine and manifested as peripheral neuropathy, autonomic neuropathy and cranial neuropathy (2). Symptoms of peripheral neuropathy are spontaneous pain, hyperalgesia and allodynia. The incidence of vincristine-induced peripheral neuropathy is $\sim 60 \%$ (3). Symptoms of vincristine-induced neuropathy are dose-dependent, and persist for several months, even following the discontinuation of treatment (4). Painful neuropathy is a major cause of unwanted interruption of vincristine treatment, and limits the dose escalation of vincristine $(5,6)$.

Since the mechanism of vincristine-induced neuropathy has not yet been clearly elucidated, drugs used for various other neuropathic conditions are empirically prescribed to treat it (7).

Theoesberiven $\mathrm{F}$ is a combination comprising Melilotus extract and proxyphylline, exerting potent anti-inflammatory, anti-edematous and analgesic effects, and clinically prescribed for the treatment of inflammatory conditions, edema, and cerebral and peripheral circulatory disorders (8). Melilotus extract has been reported to have anti-inflammatory and anti-oxidative properties and exert a suppressive effect on thermal injury in rats through the action of phagocytic cells that accumulate in the site of injury (9). In addition, a coumarinic extract of Melilotus officinalis has been demonstrated to be effective in reducing lymphedema in patients with chronic lymphedema of the upper arm caused by lymphadenectomy for breast cancer (10).

To the best of our knowledge, there have not yet been any reports concerning the effect of theoesberiven $F$ on vincristine-induced peripheral neuropathy. Therefore, whether theoesberiven $\mathrm{F}$ has anti-allodynic properties was investigated in a rat model of vincristine-induced peripheral neuropathy in the present study.

\section{Materials and methods}

Ethics and animal care. This study was conducted with formal approval from the Institutional Animal Care and Use 
Committee in the Department of Laboratory Animals of Bucheon St. Mary's Hospital of the Catholic University of Korea (Bucheon City, Korea). Animals used in this study were treated following the guidelines on the care and use of laboratory animals as decided by this institution.

Male Sprague-Dawley rats (weight, 200-250 g) were purchased from Nara Biotech (Seoul, Korea). The experiments were initiated following adjustment for 7 days in a laboratory environment. Rats were housed (2-3 animals per plastic cage) and maintained under a 12 -h light/dark cycle at $20^{\circ} \mathrm{C}$, with free access to food and water.

Vincristine-induced modeling of peripheral neuropathy. Vincristine sulfate (Hospira Inc., Lake Forest, IL, USA) was administered by injection to create the vincristine-induced peripheral neuropathy model. The treatment schedule followed was as described by Weng et al (11). Briefly, $0.1 \mathrm{mg} / \mathrm{kg}$ vincristine was administered intraperitoneally for 5 days. Following cessation for 2 days, injection was continued for the next 5 days.

Prior to the start of the injection schedule, the response to mechanical and cold stimulation was assessed to establish a baseline. On day 2 after the completion of the injections, the foot withdrawal response to von Frey filaments using a Semmes-Weinstein von Frey aesthesiometer (Stoelting Co., Wood Dale, IL, USA) was measured. If a foot withdrawal response occurred when a filament $<4 \mathrm{~g}$ was applied to the hindpaw, it was considered that allodynia had developed.

Drug administration. Allodynic rats were randomly allocated into a control group and three experimental groups (TF 0.1, TF 0.25 and TF 0.5 ). The control group (NS, $n=6$ ) received $1 \mathrm{ml} / \mathrm{kg} 0.9 \%$ normal saline. The TF 0.1 group $(\mathrm{n}=8)$ received $0.1 \mathrm{mg} / \mathrm{kg}$ theoesberiven F (Theoesberiven F inj., Dai Han Pharm, Kyeongido, South Korea) intraperitoneally. The TF 0.25 group $(\mathrm{n}=8)$ received $0.25 \mathrm{mg} / \mathrm{kg}$ theoesberiven $\mathrm{F}$, and the TF 0.5 group $(n=8)$ received $0.5 \mathrm{mg} / \mathrm{kg}$ theoesberiven $\mathrm{F}$. The doses of theoesberiven $\mathrm{F}$ were decided by preliminary testing (data not shown).

Pain behavioral tests. Behavioral tests were conducted in a similar manner as in our previous study (12). The pain behavioral tests were conducted at fixed times (1:00-6:00 p.m.) to avoid circadian rhythm errors. Following intraperitoneal treatment, the rats were placed on metal mesh covered with a plastic dome to measure mechanical and cold allodynia, as described below.

Mechanical and cold allodynia were assessed prior to drug administration and also at 15, 30, 60, 90, 120,150 and $180 \mathrm{~min}$ after administration.

Measurement of mechanical allodynia. von Frey filaments $(1.0,1.4,2.0,4.0,6.0,8.0,10.0,15.0$ and $26.0 \mathrm{~g})$ were used to measure the paw withdrawal threshold for mechanical stimuli. The third metatarsal bone area of left hind paw was stimulated with von Frey filaments at 3- to 4-sec intervals, starting with the thinnest filament $(1.0 \mathrm{~g})$. The paw withdrawal threshold was defined as the minimal pressure level [in grams $(\mathrm{g})]$ at which the withdrawal response occurred. If the withdrawal response did not occur with the strongest hair ( $26 \mathrm{~g})$, then the threshold was recorded as $26.0 \mathrm{~g}$.
Measurement of cold allodynia. Acetone was applied to the plantar surfaces of left hind paw, and the number of foot withdrawal responses (lifting, shaking, or licking) was counted. Application of acetone was repeated 5 times with an interval of 3-5 min between each test. The paw withdrawal frequency to acetone was defined as a percentage response frequency as follows: number of paw withdrawals/number of trials x 100 .

Statistical analysis. SAS software, version 9.3 (SAS Institute, Cary, NC, USA) was used to conduct the analysis. Results are expressed as the mean \pm standard error of the mean. Repeated-measures analysis of variance was used to evaluate the differences, according to the treatment group and time, followed by post hoc Dunn's test. $\mathrm{P}<0.05$ was considered to indicate a statistically significant difference.

\section{Results}

Mechanical allodynia. Administration of $0.1 \mathrm{mg} / \mathrm{kg}$ theoesberiven $\mathrm{F}$ increased the paw withdrawal threshold significantly at $90 \mathrm{~min}$ after drug administration compared with that of the control group. The individual values were $1.2 \pm 0.1,10.0 \pm 1.0^{*}, 5.9 \pm 0.9^{*}, 5.5 \pm 0.7^{*} 3.2 \pm 0.6^{*}, 1.7 \pm 0.4$, $1.5 \pm 0.3$ and $1.2 \pm 0.1 \mathrm{~g}$ before and at $15,30,60,90,120$, 150 and $180 \mathrm{~min}$ after $0.1 \mathrm{mg} / \mathrm{kg}$ TF administration, respectively ( $\mathrm{P}<0.05)$.

Administration of $0.25 \mathrm{mg} / \mathrm{kg}$ theoesberiven $\mathrm{F}$ increased the paw withdrawal threshold significantly for $120 \mathrm{~min}$ after drug administration compared with that of the control group. The individual values were $1.3 \pm 0.2,16 \pm 2.4^{*}, 8.2 \pm 1.0^{*}, 7.7 \pm 1.1^{*}$, $5.4 \pm 0.8^{*}, 3.9 \pm 0.6^{*}, 1.9 \pm 0.3$ and $1.2 \pm 0.2 \mathrm{~g}$ before and at 15,30 , $60,90,120,150$ and $180 \mathrm{~min}$ after $0.25 \mathrm{mg} / \mathrm{kg}$ TF administration, respectively ( $\mathrm{P}<0.05)$.

Administration of $0.5 \mathrm{mg} / \mathrm{kg}$ theoesberiven F increased the paw withdrawal threshold significantly for $120 \mathrm{~min}$ after drug administration compared with that of the control group. The individual values were $1.1 \pm 0.1,21.1 \pm 1.0^{*}, 13.1 \pm 1.5^{*}, 9.4 \pm 1.5^{*}$, $5.7 \pm 0.7^{*}, 4.8 \pm 0.9^{*}, 2.3 \pm 0.8$ and $1.2 \pm 0.1 \mathrm{~g}$ before and at 15,30 , $60,90,120,150$ and $180 \mathrm{~min}$ after $0.5 \mathrm{mg} / \mathrm{kg}$ TF administration, respectively ("P<0.05) (Fig. 1).

Cold allodynia. Following the administration of $0.1 \mathrm{mg} / \mathrm{kg}$ theoesberiven $\mathrm{F}$, the withdrawal frequency did not change significantly compared with that of the control group $(85.0 \pm 5.0,32.5 \pm 3.7,45.0 \pm 9.8,57.5 \pm 8.0,62.5 \pm 4.5,72.5 \pm 6.5$ and $75.0 \pm 6.3 \%$ before and at $15,30,60,90,120,150$ and $180 \mathrm{~min}$ after $0.1 \mathrm{mg} / \mathrm{kg}$ TF administration, respectively).

The administration of theoesberiven $\mathrm{F}$ reduced the withdrawal frequency to acetone application from 15 to $30 \mathrm{~min}$ at a $0.25 \mathrm{mg} / \mathrm{kg}$ dosage $\left(75.0 \pm 5.0,27.5 \pm 5.3^{*}, 30.0 \pm 10.0^{*}\right.$, $50.0 \pm 6.5,57.5 \pm 11,60.0 \pm 7.6,72.5 \pm 8.4$ and $77.5 \pm 5.9 \%$ before and at $15,30,60,90,120,150$ and $180 \mathrm{~min}$ after $0.25 \mathrm{mg} / \mathrm{kg}$ $\mathrm{TF}$ administration, respectively) ( $\mathrm{*}<0.05)$. Additionally the theoesberiven $\mathrm{F}$ reduced the withdrawal frequency to acetone application from 15 to $150 \mathrm{~min}$ for a $0.5 \mathrm{mg} / \mathrm{kg}$ dosage $\left(80.0 \pm 8.9,20.0 \pm 5.3^{*}, 27.5 \pm 9.2^{*}, 47.5 \pm 11.3^{*}, 52.5 \pm 10.6^{*}\right.$, $55.0 \pm 6.3^{*}, 57.5 \pm 4.5^{*}$ and $70.5 \pm 6.5 \%$ before and at $15,30,60$, $90,120,150$ and $180 \mathrm{~min}$ after $0.5 \mathrm{mg} / \mathrm{kg}$ TF administration, respectively) $\left({ }^{*} \mathrm{P}<0.05\right)$, as compared with the pre-administration values (Fig. 2). 


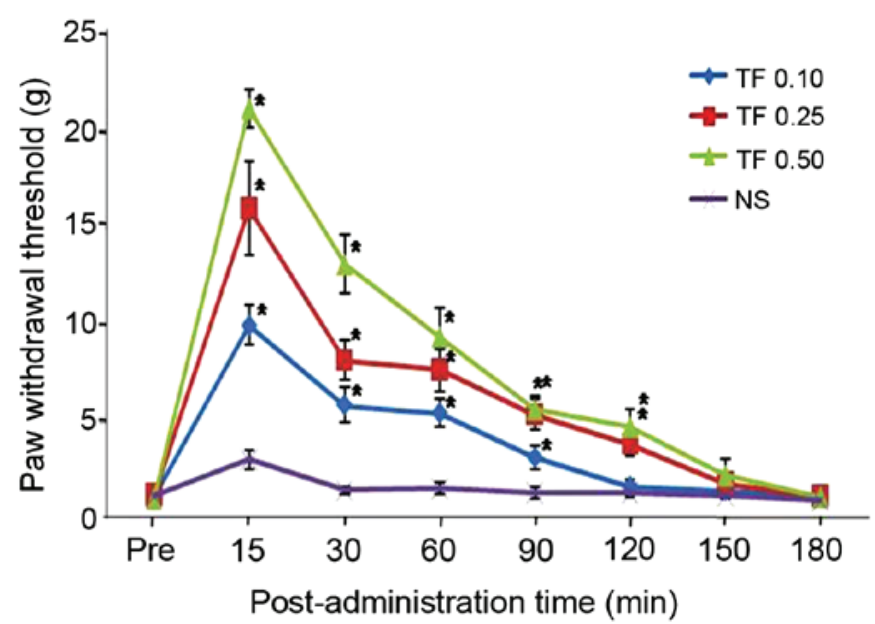

Figure 1. Effects of theoesberiven $F$ treatments on mechanical allodynia. The withdrawal threshold was measured before (Pre) and after the intraperitoneal administration of normal saline (NS), and $0.1 \mathrm{mg} / \mathrm{kg}$ (TF 0.1 ), $0.25 \mathrm{mg} / \mathrm{kg}$ (TF 0.25 ) and $0.5 \mathrm{mg} / \mathrm{kg}$ (TF 0.5) theoesberiven F. Results are expressed as mean \pm standard error of the mean. ${ }^{*} \mathrm{P}<0.05$ vs. the NS group.

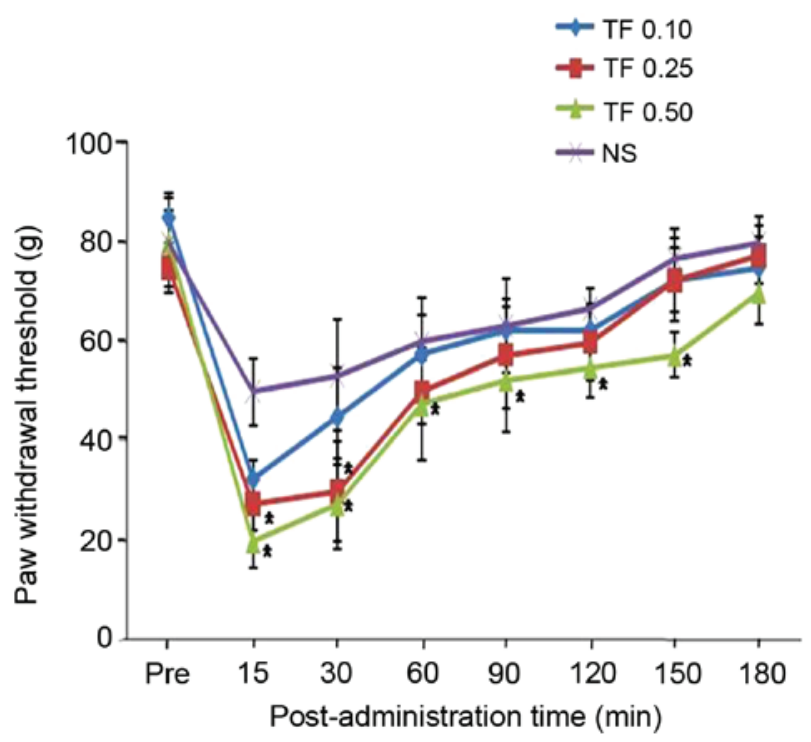

Figure 2. Effects of theoesberiven F treatment on cold allodynia. The response frequencies were measured before (Pre) and after the intraperioneal administration of normal saline (NS), and $0.1 \mathrm{mg} / \mathrm{kg}$ (TF 0.1$), 0.25 \mathrm{mg} / \mathrm{kg}$ (TF 0.25), and $0.5 \mathrm{mg} / \mathrm{kg}$ (TF 0.5) theoesberiven F. Results are expressed as mean \pm standard error of the mean. ${ }^{*} \mathrm{P}<0.05$ vs. pre-administration values

\section{Discussion}

To the best of our knowledge, the present study is the first to report that theoesberiven $\mathrm{F}$ shows an anti-allodynic effect in a vincristine-induced neuropathic rat model.

The theoesberiven F formulation contains $1.5 \mathrm{ml}$ Melilotus extract and $240 \mathrm{mg}$ proxyphylline per $2 \mathrm{ml}$. Melilotus extract contains various components such as melilotoside, a glycoside that releases glucose and coumaric acid, flavones, volatile oils, resins and tannins; of these, $0.4-0.9 \%$ coumaric acid is transformed into coumarin (13). Proxyphylline is a bronchodilator with a methylxanthine structure, similar to theophylline (14). It has also been reported to have vasodilatory and cardiac stimulatory effects (15). The mechanism by which theoesberiven Fexerted an anti-allodynic effect in vincristine-induced neuropathy in the present study is unclear.

Similar to other neuropathic pain conditions, an inflammatory process is known to play an essential role in the development of vincristine-induced neuropathy (16). Vincristine injection induces macrophage infiltration and increases in the levels of interleukin-6 (IL-6) and tumor necrosis factor- $\alpha$ (TNF- $\alpha$ ) in the sciatic nerve section of mice, resulting in inflammation in the peripheral nervous system (17-19). In addition, microglial and astrocytic activation has been reported in the lumbar spinal cord of rats following vincristine injection (20). Kiguchi et al (21) reported glial cell activation and upregulation of TNF- $\alpha$ in the spinal cords of mice following vincristine treatment, suggesting a potential role of neuroinflammation in the central nervous system in vincristine-induced neuropathy.

Tao et al (22) reported that in a cellular model comprising lipopolysaccharide-stimulated RAW 264.7 cells, an ethyl acetate fraction of Melilotus suaveolens Ledeb reduced the production of pro-inflammatory cytokines, including IL-6 and TNF- $\alpha$ via the suppression of nuclear factor- $\kappa \mathrm{B}$ activation. Furthermore, coumaric acid, a component of Melilotus extract, has been reported to exert an anti-inflammatory effect by reducing the expression of TNF- $\alpha$ (23). In addition, a coumarin derivative has been shown to protect against neurotoxicity via a improved mitochondrial function (24). Therefore, the anti-inflammatory actions of theoesberiven $\mathrm{F}$ and its components might exert a protective effect against the inflammatory process induced by vincristine injection, decreasing the allodynia.

Oxidative stress plays an important role in the expression of pain in various neuropathic pain models, including sciatic nerve transection, diabetic neuropathy and spinal nerve ligation, and the administration of anti-oxidants decreases the pain (25-27). While oxidative stress is an important factor in the activity of anticancer agents, it may also induce the development of neuropathic pain $(28,29)$. The concentrations of thiobarbituric acid reactive substances (TBARS) and superoxide anion have been observed to increase after vincristine treatment $(30,31)$. Furthermore, Melilotus extract has been shown to inhibit the formation of TBARS, the prooxidant $\mathrm{H}_{2} \mathrm{O}_{2}$ and superoxide anion in a concentration-dependent manner $(32,33)$. Therefore, the anti-allodynic activity of theoesberiven F observed in the present study may be attributed to the antioxidative effect of Melilotus extract.

Nitric oxide (NO) is involved in synaptic transmission in the central and peripheral nervous systems (34), intensifying pain at a high concentration and reducing pain at a low concentration (35). In vincristine-induced neuropathy, the reported effects of NO and nitric oxide synthase (NOS) on the pain are conflicting. Kamei et al (36) reported that vincristine administration decreased the levels of NO metabolites, cGMP and protein levels of neuronal NOS in the spinal cord, and a NOS inhibitor reversed the analgesic effect of a NOS substrate, while Bujalska and Gumułka reported that NOS inhibitors prevented the development of hyperalgesia induced by vincristine administration (37). In an inflammatory cellular model, Melilotus extract decreased the secretion of NO and expression of inducible NOS in a dose-dependent manner (38). The role that the effect of Melilotus extract on NO and NOS plays 
in the treatment of vincristine-induced neuropathy is unclear. Melilotus extract exert anti-allodynic effects by rebalancing the changes of NO and NOS induced by vincristine injection.

It is not known whether proxyphylline has an anti-inflammatory effect or anti-oxidative properties. Therefore, its role in the effects observed in the present study is not clear.

In conclusion, the intraperitoneal administration of theoesberiven $F$ reduced mechanical and cold allodynia in a vincristine-induced neuropathic rat model. The mechanism of anti-allodynia of theoesberiven $\mathrm{F}$ is hypothesized to be a combination of an anti-inflammatory effect, an anti-oxidative effect and effects on NO and NOS production. Further clinical studies are necessary before the clinical use of theoesberiven $\mathrm{F}$ in patients with vincristine-induced neuropathy can be recommended.

\section{Acknowledgements}

Statistical consultation was supported by the Catholic Research Coordinating Center of the Korea Health 21 R\&D Project (grant no. A070001), Ministry of Health \& Welfare, Republic of Korea.

\section{References}

1. Raj TA, Smith AM and Moore AS: Vincristine sulfate liposomal injection for acute lymphoblastic leukemia. Int J Nanomedicine 8: 4361-4369, 2013.

2. Legha SS: Vincristine neurotoxicity. Pathophysiology and management. Med Toxicol 1: 421-427, 1986.

3. Watkins SM, Griffin JP: High incidence of vincristine-induced neuropathy in lymphomas. Br J Med 1: 610-612, 1978.

4. Glendenning JL, Barbachano Y, Norman AR, Dearnaley DP, Herwich A and Huddart RA: Long-term neurologic and peripheral vascular toxicity after chemotherapy treatment of testicular cancer. Cancer 116: 2322-2331, 2010.

5. Verstappen CC, Koeppen S, Heimans JJ, Huijgens PC, Scheulen ME, Strumberg D, Kiburg B and Postma TJ: Dose-related vincristine-induced peripheral neuropathy with unexpected off-therapy worsening. Neurology 64: 1076-1077. 2005.

6. Postma TJ, Benard BA, Huijgens PC, Ossenkoppele GJ and Heimans JJ: Long-term effects of vincristine on the peripheral nervous system. J Neurooncol 15: 23-27, 1993

7. Lynch JJ III, Wade CL, Zhong CM, Mikusa JP and Honore P: Attenuation of mechanical allodynia by clinically utilized drugs in a rat chemotherapy-induced neuropathic pain model. Pain 110 56-63, 2004

8. Moon MS and Lee IJ: Clinical experience of Theo-Esberiven for the patients with acute musculoskeletal injuries and postoperative inflammation. New Med J 9: 133-137, 1985 (In Korean).

9. Nishikawa M, Yamashita A, Ando K and Mitsuhiro S: The suppressive effect of Melilotus extract on the thermal edema of rats. Nihon Yakurigaku Zasshi 81: 193-209, 1983 (In Japanese).

10. Pastura G, Mesiti M, Saitta M, Romeo D, Settineri N, Maisano R, Petix M and Giudice A: Lymphedema of the upper extremity in patients operated for carcinoma of the breast: Clinical experience with coumarinic extract from Melilotus officinalis. Clin Ter 150 403-408, 1999 (In Italian).

11. Weng HR, Cordella JV and Dougherty PM: Changes in sensory processing in the spinal dorsal horn accompany vincristine-induced hyperalgesia and allodynia. Pain 103: 131-138, 2003

12. Park HJ, Lee HG, Kim YS, Lee JY, Jeon JP, Park C and Moon DE: Ginkgo biloba extract attenuates hyperalgesia in a rat model of vincristine-induced peripheral neuropathy. Anesth Analg 115: 1228-1233, 2012

13. Pleşca-Manea L, Pârvu AE, Pârvu M, Taămaş M, Buia R and Puia M: Effects of Melilotus officinalis on acute inflammation. Phytother Res 16: 316-319, 2002.

14. L Tivenius: Comparison of drugs for asthma. Br Med J 2: 773 , 1971.
15. Takeda K, Katano Y, Nakagawa Y, Tsukada T, Nakazawa M Otorii T and Imai S: Effects of aminopylline, proxyphylline and a proxyphylline-Melilotus extract-rutin mixture (theoesberiven) on the heart and the coronary circulation. Jpn J Pharmacol 27: 709-720, 1977.

16. Kiguchi N, Maeda T, Kobayashi Y, Saika F and Kishioka S: Involvement of inflammatory mediators in neuropathic pain caused by vincristine. Int Rev Neurobiol 85: 179-190, 2009.

17. Uçeyler N, Kobsar I, Biko L, Ulzheimer J, Levinson SR, Martini R and Sommer C: Heterozygous P0 deficiency protects mice from vincristine-induced polyneuropathy. J Neurosci Res 84: 37-46, 2006

18. Kiguchi N, Maeda T, Kobayahi Y, Kondo T, Ozaki M and Kishioka S: The critical role of invading peripheral macrophage-derived interleukin-6 in vincristine-induced mechanical allodynia in mice. Eur J Pharmacol 592: 87-92, 2008.

19. Muthuraman A, Singh N and Jaggi AS: Protective effect of Acorus calamus $\mathrm{L}$. in rat model of vincristine induced painful neuropathy: An evidence of anti-inflammatory and anti-oxidative activity. Food Chemi Toxicol 49: 2557-2563, 2011

20. Sweitzer SM, Pahl JL and DeLeo JA: Propentofylline attenuates vincristine-induced peripheral neuropathy in the rat. Neurosci Lett 400: 258-261, 2006.

21. Kiguchi N, Maeda T, Kobayashi Y and Kishioka S: Up-regulation of tumor necrosis factor-alpha in spinal cord contributes to vincristine-induced mechanical allodynia in mice. Neurosci Lett 445: 140-143, 2008.

22. Tao JY, Zheng GH, Zhao L, Wu JG, Zhang XY, Zhang SL, Huang ZJ, Xiong FL and Li CM: Anti-inflammatory effects of ethyl acetate fraction from Melilotus suaveolens Ledeb on LPS-stimulated RAW 264.7 cells. J Ethnopharmacol 123: 97-105, 2009.

23. Pragasam SJ, Venkatesan V and Rasool M: Immunomodulatory and anti-inflammatory effect of $p$-coumaric acid, a common dietary polyphenol on experimental inflammation in rats. Inflammation 36: 169-176, 2013.

24. Song XY, Hu JF, Sun MN, Li ZP, Wu DH, Ji HJ, Yuan YH, Zhu ZX, Han N, Liu G and Chen NH: IMM-H004, a novel coumarin derivative compound, protects against amyloid beta-induced neurotoxicity through a mitochondrial-dependent pathway. Neuroscience 242: 28-38, 2013.

25. Scheid T, Bosco LD, Guedes RP, Pavanato MA, Belló-Klein A and Partata WA: Sciatic nerve transcetion modulates oxidative parameters in spinal and supraspinal regions. Neurochem Res 38: 935-942, 2013.

26. Zhang YP, Eber A, Yuan Y, Yang Z, Rodriguez Y, Levitt RC, Takacs P and Candiotti KA: Prophylactic and antinociceptive effects of coenzyme Q10 on diabetic neuropathic pain in a mouse model of type 1 diabetes. Anesthesiology 118: 945-954, 2013.

27. Yowtak J, Lee KY, Kim HY, Wang J, Kim HK, Chung K and Chung JM: Reactive oxygen species contributes to neuropathic pain by reducing spinal GABA release. Pain 152: 844-852, 2011.

28. Sun Y, Huang L, Mackenzie GG and Rigas B: Oxidative stress mediates through apoptosis the anticancer effect of phospho-nonsteroidal anti-inflammatory drugs: implications for the role of oxidative stress in the action of anticancer agents. J Pharmacol Exp Ther 338: 775-783, 2011.

29. Carozzi VA, Canta A and Chiorazzi A: Chemotherapy-induced peripheral neuropathy: What do we know about mechanisms? Neurosci Lett 596: 90-107, 2015

30. Wozniak A, Drewa G, Woźniak B, Schachtschabel DO, Mila-Kierzenkowska C, Drewa T, Olszewska-Słonina D and Sopońska M: The effect of antitumor drugs on oxidative stress in B16 and S91 melanoma cells in vitro. Med Sci Monit 11: BR22-BR29, 2005

31. Muthuraman A and Singh N: Attenuating effect of hydroalcoholic extract of Acorus calamus in vincristine-induced painful neuropathy in rats. J Nat Med 65: 480-487, 2011.

32. Fiorentino A, D'Abrosca B, Pacifico S, Golino A, Mastellone C, Oriano P and Monaco P: Reactive oxygen species scavenging activity of flavone gylcosides from Melilotus neapolitana. Molecules 12: 263-270, 2007.

33. Braga PC, Sasso MD, Lattuada N, Marabini L, Calò R, Antonacci R, Bertelli A, Falch M and Verducci P: Antioxidant activity of Melilotus officinalis extract investigated by means of the radical scavenging activity, the chemiluminescence of human neutrophil bursts and lipoperoxidation assay. J Med Plants Res 7: 358-365, 2013

34. Schuman EM and Madison DV: Nitric oxide and synaptic function. Annu Rev Neurosci 17: 153-183, 1994. 
35. Prado WA, Schiavon VF and Cunha FQ: Dual effect of local application of nitric oxide donors in a model of incision pain in rats. Eur J Pharmacol 441: 57-65, 2002.

36. Kamei J, Tamura N and Saitoh A: Possible involvement of the spinal nitric oxide/cGMP pathway in vincristine-induced painful neuropathy in mice. Pain 117: 112-120, 2005.
37. Bujalska M and Gumułka SW: Effect of cyclooxygenase and nitric oxide synthase inhibitors on vincristine induced hyperalgesia in rats. Pharmacol Rep 60: 735-741, 2008.

38. Zhao L, Tao JY, Zhang SL, Pang R, Jin F, Dong JH and Guo YJ: Inner anti-inflammatory mechanisms of petroleum ether extract from Melilotus suaveolens Ledeb. Inflammation 30: 213-223, 2007. 